\title{
Peer pressure and bullying among school going adolescents in the district of Kandy
}

\author{
D.S. Dissanayake ${ }^{1}$, W.M.M.W.N.C. Weeratunge ${ }^{2}$, G.M.N.S. Gaspe ${ }^{2}$, A.G.O.N.A. Gamage ${ }^{2}$
}

\begin{abstract}
Objectives

To determine the extent, common types and the impacts of negative peer pressure and bullying among adolescents within the school environment.

\section{Methodology}

A cross sectional study was carried out including Sinhalese adolescents in grades 9, 10 and 11 in the district of Kandy. Twelve schools were selected randomly to represent each category of schools namely $1 \mathrm{AB}, 1 \mathrm{C}$ and 2 and a class was considered as a cluster. Details on events and experiences as victims of negative peer pressure and bullying were collected using a self-administered questionnaire.
\end{abstract}

\section{Results}

The sample consisted of 896 students with a mean age of 15 years $(\mathrm{SD}=0.86)$. Fifty two percent $(\mathrm{n}=466)$ were boys. Peer pressure on substance use and of financial type was significantly more for boys. Peer pressure for sexual activities was reported by $14.6 \%$ of boys and $11.2 \%$ of girls. A significantly higher proportion of boys $(78.1 \%)$, were victims of physical bullying than girls $(26.5 \%)(\mathrm{p}<0.001)$. More girls were victims of verbal bullying $(82.1 \%)$ than boys $(50 \%)(\mathrm{p}<0.001)$. Of the sample, $53.3 \%$ were victims of relational bullying. Of the boys, $16.7 \%, 12.2 \%$ and $10.3 \%$ were compelled to smoke, use alcohol or use illegal abusive substances. Drop in school performance, staying away from school and extra-curricular activities, engaging in homo-sexual and hetero-sexual acts, feeling of hatred and suicidal thoughts were some of the undesirable impacts reported.

\section{Conclusion}

High prevalence and the harmful effects of negative peer pressure and bullying observed provide compelling reasons to initiate interventions.

Key words: peer pressure, adolescents, bullying

\section{Introduction}

Peer pressure refers to the influence exerted by a peer group to encourage a person to change his or her attitudes, values or behaviour in order to conform to the group. It has a great influence on adolescent behavior and reflects the desire to fit in to a group and be accepted by others. Peers can have both positive and negative influence on each other. Negative peer pressure among adolescents is identified as an important predictor of antisocial behaviours such as smoking, alcohol abuse, illicit drug use, sexual harassment and youth violence (1-5).

Bullying is usually defined as a specific form of aggression, which is intentional, repeated, and involves a disparity of power between the victims and perpetrators (6). Most common bullying acts are physical or verbal. Relational bullying is another form of bullying, which involves mainly spreading rumors and social exclusion (7). In developed countries, bullying using electronic means such as internet and mobile phones (cyber bullying) is aggravating the problem further (7). Though bullying in schools has been viewed as a natural process over the years, the consequences of bullying on victims has led to concern $(8,9)$.

As research on peer pressure and bullying among adolescents is lacking in Sri Lanka and as the nature of both these problems can vary according to the culture and values of a society across countries, a study among Sri Lankan adolescents was important. The aim of this study was to determine the extent and the common types of negative peer pressure and bullying within the school environment, how they differ according to sex and other factors, and to find out the consequences of these on Sri Lankan adolescents. Since both peer pressure and bullying are inter-related and common to school going adolescents, both these aspects were studied together.

\section{Methodology}

A cross sectional study was carried out among adolescents in grades 9,10 and 11 attending the Sinhala medium government schools in the Central

1. Senior Lecturer, Department of Community Medicine, Faculty of Medicine, University of Peradeniya

2. Temporary Lecturer, Department of Community Medicine, Faculty of Medicine, University of Peradeniya Correspondence : devanis12002@yahoo.com 
Province, Kandy Zone, Gangawata Division. Out of 48 Sinhala medium schools having students in grades 9, 10 and 11 in Gangawata division, 12 schools were randomly selected to represent each category of schools namely 1AB ( 3 schools), 1C (4 schools) and 2 (5 schools). According to the categorization of schools by Ministry of Education, the category $1 \mathrm{AB}$ is considered the best having all subject streams while category 2 caters only up to ordinary level. A class was considered as a cluster and classes were selected randomly from all 3 grades. A design effect of 2 was considered to calculate the required sample size $(n=908)$.

A pre-tested self administered questionnaire having both closed and open ended questions was used to collect data. The subjects were asked to report in detail all the events that they could recall as bully victims and their experiences under peer pressure from grade 6 to date. Information was gathered only about the acts of bullying by fellow students but not by teachers. Also, the data were specifically on bullying and peer pressure which took place only within the school environment, both during and after school.

Data analysis was carried out using the Statistical Package for Social Sciences (SPSS) 17th version.
Since students reported various types of bullying and negative peer pressure, they were categorized under few main types for further analysis. The peer pressure for homosexual and heterosexual acts was considered under sexual peer pressure.

The ethical approval was obtained from the Committee on Research and Ethical Review, Faculty of Medicine, University of Peradeniya. The permission to carry out the study in selected schools was taken from the Provincial Department of Education, Central Province. Informed consent was obtained from parents.

\section{Results}

Though the response rate was $100 \%$, data collected from few students had to be removed due to incompleteness or irrelevant information given. The final sample consisted of 896 students. The age ranged from 13 years and 4 months to 17 years with a mean of 15 years $(\mathrm{SD}=0.86)$. Fifty two percent of them were males $(n=466)$ and $91.5 \%$ of the study population were day scholars. Approximately equal sex distribution was observed in the total study sample and within the 3 categories of schools.

Of the study sample, $67.8 \%(95 \% \mathrm{CI}=63.6 \%-72 \%)$ of the boys and $24.3 \%(95 \% \mathrm{CI}=20.3 \%-28.3 \%)$ of

Table 1: Commonly reported acts of bullying according to sex

\begin{tabular}{|l|c|c|c|c|c|c|}
\hline \multirow{2}{*}{ Act of Bullying } & \multicolumn{2}{|c|}{$\begin{array}{c}\text { Girls } \\
(\mathbf{n = 4 3 0})\end{array}$} & \multicolumn{2}{c|}{$\begin{array}{c}\text { Boys } \\
(\mathbf{n}=\mathbf{4 6 6})\end{array}$} & \multicolumn{2}{c|}{$\begin{array}{c}\text { Total } \\
(\mathbf{n}=\mathbf{8 9 6})\end{array}$} \\
\cline { 2 - 7 } & $\boldsymbol{n}$ & $\%$ & $\boldsymbol{n}$ & $\%$ & $\boldsymbol{n}$ & $\%$ \\
\hline Physical harassments using limbs & 46 & 10.7 & 285 & 61.1 & 331 & 36.9 \\
\hline Being scolded in harsh language & 174 & 40.5 & 62 & 13.3 & 236 & 26.3 \\
\hline $\begin{array}{l}\text { Subjected to humiliation, use of } \\
\text { nicknames and passing hints }\end{array}$ & 157 & 36.5 & 47 & 10.1 & 204 & 22.7 \\
\hline $\begin{array}{l}\text { Spreading rumours to harm good } \\
\text { reputation }\end{array}$ & 72 & 16.7 & 19 & 4.1 & 91 & 10.1 \\
\hline Subjected to verbal threat & 13 & 3 & 48 & 10.3 & 61 & 6.8 \\
\hline Touching body without permission & 43 & 10 & 15 & 3.2 & 58 & 6.4 \\
\hline Breaking friendship & 42 & 9.8 & 1 & 0.2 & 43 & 4.8 \\
\hline Disturbing learning process & 17 & 3.9 & 16 & 3.4 & 33 & 3.6 \\
\hline $\begin{array}{l}\text { Physical harassment using other } \\
\text { objects }\end{array}$ & 21 & 4.8 & 10 & 2.1 & 31 & 3.4 \\
\hline $\begin{array}{l}\text { Stealing money or destroying } \\
\text { belongings }\end{array}$ & 15 & 3.5 & 12 & 2.6 & 27 & 3 \\
\hline Isolation & 24 & 5.6 & 8 & 1.7 & 32 & 3.5 \\
\hline $\begin{array}{l}\text { Cutting hair/ Alteration of dress/ } \\
\text { removal of shoes by force }\end{array}$ & 25 & 5.5 & 1 & 0.2 & 26 & 2.9 \\
\hline
\end{tabular}


Table 2: Commonly reported acts of negative peer pressure according to sex

\begin{tabular}{|c|c|c|c|c|c|c|}
\hline \multirow{2}{*}{ Act of negative peer pressure } & \multicolumn{2}{|c|}{ Girls $(n=430)$} & \multicolumn{2}{|c|}{ Boys $(n=466)$} & \multicolumn{2}{|c|}{ Total $(n=896)$} \\
\hline & $n$ & $\%$ & $n$ & $\%$ & $n$ & $\%$ \\
\hline Compelled to contribute money & 83 & 19.3 & 311 & 66.7 & 394 & 43.9 \\
\hline Compelled for sexual activities & 48 & 11.2 & 68 & 14.6 & 116 & 12.9 \\
\hline Forced to start a love affair & 87 & 20.2 & 10 & 2.1 & 97 & 10.8 \\
\hline Forced to harass another person & 5 & 1.1 & 54 & 11.6 & 59 & 6.6 \\
\hline Compelled to smoke & 1 & 0.002 & 78 & 16.7 & 79 & 8.8 \\
\hline Compelled to use alcohol & 0 & 0.00 & 57 & 12.2 & 57 & 6.4 \\
\hline $\begin{array}{l}\text { Compelled to use illegal abusive } \\
\text { substances }\end{array}$ & 1 & 0.002 & 48 & 10.3 & 49 & 5.5 \\
\hline Forced to watch pornography & 3 & 0.7 & 21 & 4.5 & 24 & 2.6 \\
\hline $\begin{array}{l}\text { Forced to purchase food or other } \\
\text { items for other students }\end{array}$ & 11 & 2.6 & 14 & 3 & 25 & 2.7 \\
\hline Forced to kiss another & 16 & 3.7 & 8 & 1.7 & 24 & 2.6 \\
\hline
\end{tabular}

the girls have been subjected to one or more type of negative peer pressure. Sixty eight percent of boys $(95 \% \mathrm{CI}=63.8 \%-72.2 \%)$ and $51.2 \%(95 \% \mathrm{CI}=$ $46.5 \%-55.9 \%$ ) of girls were victims of some kind of a bully act. Commonly reported acts of bullying and negative peer pressure are given in Tables 1 and 2 respectively. Sixty one percent of the boys have been subjected to physical harassment using limbs while $40.5 \%$ of the girls have been scolded with harsh language. Under physical type of bullying, 15 boys said that they were assaulted after covering their heads with a cloth which they referred to as 'boothayagaseema' (attacks by ghosts).

Nearly $67 \%$ of the boys have been compelled to contribute money for variouspurposes. The commonest type of negative peer pressure for girls was the pressure exerted on them to start love affairs with opposite sex $(20.2 \%)$. Of the boys, $16.7 \%$, $12.2 \%$ and $10.3 \%$ were compelled to smoke, use alcohol or use illegal abusive substances respectively. Only 2 girls reported of substance abuse under peer pressure. The distribution of types of bullying and negative peer pressure according to socio-demographic characteristics of adolescents is shown in Table 3. A significantly higher proportion of boys were victims of physical bullying when compared with that of girls $(\mathrm{p}<0.001)$. More girls were victims of verbal bullying than boys $(\mathrm{P}<$ 0.001). Peer pressures of financial type and on substance abuse were significantly more among boys (Table 3 ). Peer pressure for sexual activities was experienced by $14.6 \%$ of boys and $11.2 \%$ of girls. 
Table 3: Types of bullying and negative peer pressure according to socio-demographic characteristics of adolescents

\begin{tabular}{|c|c|c|c|c|c|c|c|c|c|c|c|c|}
\hline & \multicolumn{6}{|c|}{ Bullying } & \multicolumn{6}{|c|}{ Peer Pressure } \\
\hline & \multicolumn{2}{|c|}{ Physical } & \multicolumn{2}{|c|}{ Relational } & \multicolumn{2}{|c|}{ Verbal } & \multicolumn{2}{|c|}{ Financial } & \multicolumn{2}{|c|}{ Sexual } & \multicolumn{2}{|c|}{$\begin{array}{c}\text { Substance } \\
\text { use }\end{array}$} \\
\hline & $n$ & $\%$ & $n$ & $\%$ & $n$ & $\%$ & $n$ & $\%$ & $n$ & $\%$ & $n$ & $\%$ \\
\hline \multirow{2}{*}{\multicolumn{13}{|c|}{ Gender }} \\
\hline & & & & & & & & & & & & \\
\hline $\begin{array}{l}\text { Male }(\mathrm{n}= \\
466)\end{array}$ & 364 & 78.1 & 235 & 50.4 & 233 & 50 & 334 & 21.3 & 68 & 14.6 & 107 & 22.9 \\
\hline $\begin{array}{l}\text { Female }(\mathrm{n}= \\
430)\end{array}$ & 114 & 26.5 & 243 & 56.5 & 353 & 82.1 & 92 & 71.6 & 48 & 11.2 & 02 & 0.47 \\
\hline *p value & \multicolumn{2}{|c|}{$<0.001$} & \multicolumn{2}{|c|}{0.07} & \multicolumn{2}{|c|}{$<0.001$} & \multicolumn{2}{|c|}{$\frac{1}{<0.001}$} & \multicolumn{2}{|c|}{0.13} & \multicolumn{2}{|c|}{$\frac{1}{<0.001}$} \\
\hline \multicolumn{13}{|l|}{$\begin{array}{l}\text { Category of } \\
\text { School }\end{array}$} \\
\hline $\begin{array}{l}1 \mathrm{AB}(\mathrm{n}= \\
266)\end{array}$ & 143 & 53.7 & 154 & 57.8 & 200 & 75.2 & 121 & 45.4 & 49 & $\mid 18.4$ & 47 & 17.6 \\
\hline $1 \mathrm{C}(\mathrm{n}=481)$ & 238 & 49.4 & 243 & 50.5 & 301 & 62.6 & 245 & 50.9 & 46 & 9.5 & 46 & 9.6 \\
\hline $2(n=149)$ & 97 & 65.1 & 81 & 54.3 & 85 & 57 & 60 & 40.2 & 21 & 14.1 & 16 & 10.7 \\
\hline$*$ p value & \multicolumn{2}{|c|}{$\frac{1}{0.004}$} & \multicolumn{2}{|c|}{0.148} & \multicolumn{2}{|c|}{$<0.001$} & \multicolumn{2}{|c|}{$\frac{1}{0.05}$} & \multicolumn{2}{|c|}{0.002} & \multicolumn{2}{|c|}{0.006} \\
\hline \multicolumn{13}{|l|}{$\begin{array}{l}\text { Entry to } \\
\text { School }\end{array}$} \\
\hline $\begin{array}{l}\text { At grade } 1(\mathrm{n} \\
=521)\end{array}$ & 270 & 51.8 & 272 & 52.2 & 330 & 63.3 & 233 & 44.7 & 65 & 12.4 & 56 & 10.7 \\
\hline $\begin{array}{l}\text { Grade } 2-5 \\
(\mathrm{n}=108)\end{array}$ & 55 & 50.9 & 48 & 44.4 & 71 & 65.7 & 57 & 52.7 & 14 & 12.9 & 14 & 12.9 \\
\hline $\begin{array}{l}\text { At grade } 6 \text { or } \\
\text { above } \\
(\mathrm{n}=260)\end{array}$ & 149 & 57.3 & 154 & 59.2 & 180 & 69.2 & 132 & 50.7 & 37 & 14.2 & 39 & 15.0 \\
\hline \multicolumn{13}{|l|}{$\begin{array}{l}\text { Non } \\
\text { responders(n } \\
=9)\end{array}$} \\
\hline $\begin{array}{l}\text { Total } \\
(\mathrm{n}=896)\end{array}$ & 478 & 53.3 & 478 & 53.3 & 586 & 64.5 & 426 & 47.5 & 116 & 12.9 & 109 & 12.2 \\
\hline$* \mathrm{p}$ value & & 3 & & 03 & & 26 & & 14 & & 79 & & 27 \\
\hline
\end{tabular}

\footnotetext{
* Chi-squared test
}

Category $1 \mathrm{AB}$ schools had the highest percentages of students who were subjected to verbal bullying, relational bullying and peer pressures for substance abuse and sexual activities (Table 3). However, a significantly higher proportion of adolescents in category 2 schools were victims of physical bullying $(\mathrm{p}=0.004)$. When compared with others, a higher percentage of students who have entered the school at grade 6 or above $(59.2 \%)$ were victims of relational bullying $(\mathrm{p}=0.03)$. Further, they were the victims of physical and verbal bullying and also who experienced negative peer pressure for substance 
abuse and sexual encounters more frequently than others though the difference observed was not statistically significant (Table 3 ).
The impact of bullying and negative peer pressure on these adolescents is shown in table 4 . Almost $63 \%$ of students reported that they had feelings of hatred

Table 4: Undesirable effects of bullying \& negative peer pressure on adolescents, according to sex

\begin{tabular}{|c|c|c|c|c|c|c|c|}
\hline \multirow[t]{2}{*}{ Undesirable effects } & \multicolumn{2}{|c|}{$\begin{array}{c}\text { Girls } \\
(n=430)\end{array}$} & \multicolumn{2}{|c|}{$\begin{array}{c}\text { Boys } \\
(n=466)\end{array}$} & \multicolumn{2}{|c|}{ Total $(n=896)$} & \multirow[b]{2}{*}{ *p value } \\
\hline & $n$ & $\%$ & $n$ & $\%$ & $n$ & $\%$ & \\
\hline School absenteeism & 92 & 21.4 & 112 & 24.0 & 204 & 22.8 & 0.35 \\
\hline Cutting school periods & 37 & 8.6 & 76 & 16.3 & 113 & 12.6 & 0.001 \\
\hline $\begin{array}{l}\text { Drop in school performance/ } \\
\text { rank }\end{array}$ & 120 & 27.9 & 131 & 28.1 & 251 & 28 & 0.95 \\
\hline Was disliked by teachers & 65 & 15.1 & 35 & 7.5 & 200 & 22.3 & $<0.001$ \\
\hline Was disliked by parents & 109 & 25.3 & 153 & 32.8 & 262 & 29.2 & 0.01 \\
\hline Was disliked by friends & 93 & 21.6 & 179 & 38.4 & 272 & 30.4 & $<0.001$ \\
\hline Had feelings of hatred & 279 & 64.8 & 285 & 61.1 & 564 & 62.9 & 0.25 \\
\hline $\begin{array}{l}\text { Had to stop extracurricular } \\
\text { activities }\end{array}$ & 59 & 13.7 & 107 & 22.9 & 166 & 18.5 & $<0.001$ \\
\hline $\begin{array}{l}\text { Reduction of performance in } \\
\text { extracurricular activities }\end{array}$ & 95 & 22.1 & 172 & 36.9 & 262 & 29.4 & $<0.001$ \\
\hline Stopped attending tuition classes & 60 & 13.9 & 135 & 28.9 & 195 & 21.8 & $<0.001$ \\
\hline Had to change tuition classes & 60 & 13.9 & 82 & 17.6 & 142 & 15.8 & 0.14 \\
\hline Had to change the school & 07 & 1.6 & 27 & 5.7 & 34 & 3.7 & 0.01 \\
\hline $\begin{array}{l}\text { Had to get medical advice/ } \\
\text { treatment }\end{array}$ & 18 & 4.2 & 65 & 13.9 & 83 & 9.3 & $<0.001$ \\
\hline $\begin{array}{l}\text { Had feelings of worthlessness of } \\
\text { life }\end{array}$ & 81 & 18.8 & 106 & 22.7 & 187 & 20.9 & 0.15 \\
\hline Had suicidal ideas & 34 & 7.9 & 67 & 14.3 & 101 & 11.3 & 0.002 \\
\hline Had suicidal attempts & 6 & 1.3 & 30 & 6.4 & 36 & 4 & $<0.001$ \\
\hline Had to consume alcohol & 0 & - & 57 & 12.2 & 57 & 6.4 & $\begin{array}{c}< \\
0.001 * * \\
\end{array}$ \\
\hline Had to smoke & 1 & 0.002 & 78 & 16.7 & 79 & 8.8 & $<0.001$ \\
\hline Had to consume illicit drugs & 1 & 0.002 & 48 & 10.3 & 49 & 5.5 & $<0.001$ \\
\hline Experienced homosexual acts & 6 & 1.3 & 50 & 10.7 & 56 & 6.3 & $<0.001$ \\
\hline Had heterosexual acts & 2 & 0.004 & 35 & 7.5 & 37 & 4.1 & $<0.001$ \\
\hline Had to start a love affair & 64 & 14.9 & 10 & 2.1 & 74 & 8.3 & $<0.001$ \\
\hline Had an impact other than above & - & - & - & - & 124 & 13.8 & - \\
\hline
\end{tabular}

* Chi - Squared test

** Fisher's exact test 
towards the bullies and the peers who exerted pressure on them (table 4). Nearly one fourth of both boys and girls has been absent from school and nearly one third of both sexes perceived a drop in school performance due to bullying or peer pressure. Almost $23 \%$ of boys had to stop extracurricular activities at school while $37 \%$ of boys thought their performance in extracurricular activities dropped due to peer pressure or bullying. Among boys, $10.7 \%$ and $7.5 \%$ have experienced homosexual acts and heterosexual acts respectively (table 4). Almost $15 \%$ of girls have started a love affair under these circumstances. A significantly higher percentage of boys had suicidal ideas and suicidal attempts than girls $(\mathrm{p}<0.001)$.

\section{Discussion}

Most published literature on adolescent peer pressure discuss on substance use or sexual abuse. When the questionnaire was pre-tested in the present study, adolescents came out with their concern on peer pressure to contribute money for various reasons which led the researchers' concern on financial type of peer pressure. Although not a single study has recognized this problem as a negative peer pressure on adolescents, the present study identified that $71.6 \%$ of boys and $21.3 \%$ of girls were subjected to this financial type of peer pressure.

As events such as substance use and sexual encounters are not easily forgotten, the recall bias on these would have been minimal. Though under reporting would have occurred when recalling the bullying incidents, over $50 \%$ of both boys and girls have reported their experiences as bully victims.

As the present study did not evaluate the reasons for substance use but highlighted only the proportions of adolescents using substance due to peer pressure, the figures are not quite comparable with prior research. Nevertheless, in a study carried out on substance use among $13-18$ year old adolescents in Colombo, Sri Lanka $(n=3196)$, the life time use of cigarettes, alcohol and Marijuana was 5.5\%,10\% and $1.6 \%$ among boys and $0.6 \%, 3.6 \%$ and $0.4 \%$ among girls respectively (10). Though the objective of this study was not to assess the influence of peer pressure on substance use, the findings highlighted that the source of first use was friends. Therefore, we can assume that the use of substance was mainly due to peer influence in this Colombo study too. However, the prevalence of substance use was much less among boys in the Colombo study when compared with the present study conducted in Kandy. Though overall prevalence of substance use among girls was very low in both these studies, alcohol use at least once in life time was reported by $3.6 \%$ of girls in Colombo while not a single girl in the present study admitted of having alcohol.

Peer pressure for sexual activities was reported by $12.9 \%$ of the adolescents with no significant difference in prevalence between boys and girls. Nevertheless, significantly higher proportions of boys have got involved with both homosexual and heterosexual activities than girls which highlight a better capacity among girls to resist peer pressure. A survey carried out in Nigeria has found out that the peer pressure exerted $61.2 \%$ of the influence on sexual practices of adolescents (11). Further, a research in South Africa showed that the peer pressure on both boys and girls increased the high risk sexual behavior (5). Hence, peer pressure on sexual activities is an important issue to address in reproductive health of adolescents.

Both the peer pressures for sexual activities and substance use was highest in type AB schools which are considered as better schools in our country. These schools will need more attention when implementing activities to reduce the negative peer pressure.

According to literature, the prevalence and nature of bullying varies across countries. Similar to the findings in previous studies, more boys were victims of physical bullying than girls $(7,12)$. Victimization of relational bullying was consistent with previous studies showing no significant variation with sex. However, contrary to findings in previous research, significantly higher proportion of girls in the current study was victims of verbal bullying $(7,12)$. The findings highlight how bullying could vary in different cultural settings.

Effort should be made to prevent high occurrence of bullying in smaller schools of category 2 and specially some of the bully acts observed such as 'Boothayagaseema' which can lead to serious injuries.

The students entering a school in grade 6 or later were subjected to almost all types of bullying and negative peer pressure more often than the fellow students. Most of these students were grade 5 scholarship winners. Both teachers and the parents should be made aware of this problem to minimize such incidences to help these students to adjust to the new environment.

It was difficult to identify the negative impacts of peer pressure and bullying separately as both problems led to some common negative impacts on adolescents. Even in prior research, bullied students have also reported higher rates of substance use and sexual intercourse highlighting the overlapping nature of the two problems (9). 
A drop in school performance, staying away from school and suicidal thoughts has been reported by bully victims in previous studies too $(8,13$, 14).Bringing great concern, $4 \%$ and $11.3 \%$ of the study population reported that they tried to commit suicide or had suicidal ideas respectively. Though it is not possible to discuss each and every undesirable effect experienced by victims of bullying and negative peer pressure highlighted in results, most need to be paid attention. Overall, significantly higher proportions of boys were found to have undesirable impacts. Hence, intervention programs should target specially the boys to prevent this problem and to develop the capacity to resist negative peer pressure and bullying.

In conclusion, the high prevalence and the harmful effects of negative peer pressure and bullying observed deserve special attention by educators and parents to initiate interventions.

\section{Acknowledgement}

The technical support by Mr. K.M.C.U. Champika is appreciated.

\section{References}

1. Robin SS, Johnson EO. Attitude and peer cross pressure: adolescent drug and alcohol use. Journal of Drug Education 1996; 26(1): 69 - 99.

2. Ando M, Asakura T, Ando S, Simons-Morton BG. Psychosocial factors associated with smoking and drinking among Japanese early adolescent boys and girls: Cross-sectional study. Biopsychosocial Medicine July 2007; 1:13.

3. Dielman TE, Butchart AT, Shope JT. Structural equation model tests of patterns of family interaction, peer alcohol use, and intrapersonal predictors of adolescent alcohol use and misuse. Journal of Drug Education 1993; 23(3): 273-316.

4. Epstein JA, Bang H, Botvin GJ. Which psychological factors moderate or directly affect substance use among inner city adolescents? Addictive Behaviours 2007 April, 32(4): 700 - 713.

5. Selikov TA, Ahmed N, Fisher AJ, Mathews C, Mukoma W. I am not "umqwayito": A qualitative study of peer pressure and sexual risk behaviour among young adolescents in Cape Town, South Africa. Scandinavian Journal of Public Health June 2009; 37(2): $107-112$.

6. Olweus D. Bullying at school. What we know and what we can do. Cambridge, MA: Blackwell; 1993 [accessed 12.02.2011].

7. Wang J, Iannotti RJ, Nannsel TR. School bullying among adolescents in the United States: physical, verbal, relational and cyber. Journal of Adolescent Health 2009 October, 45(4): 368-375.

8. Batsche GM, Knoff HM. Bullies and their victims: Understanding a pervasive problem in the schools. School Psychology Review 1994, 23: 165-175.
9. Fleming LC, Jacobsen KH. Bullying among middleschool students in low and middle income countries. Health Promotion International 2010 March, 25(1): $73-84$.

10. Ismail AC, Seneviratne R De A. Prevalence and pattern of substance use among secondary school students in the Colombo district. Journal of the College of Community Physicians of Sri Lanka 2008 Dec; 13(2): 17-25.

11. Egbochuku EO, Ekanem IB. Attitude of Nigerian secondary school adolescents toward sexual practices: Implications for counselling practices. European Journal of Scientific Research 2008 October; 22(2): 117-183.

12. Scheithauer H, Hayer T, Petrtmann F, Jugert G. Physical, verbal, and relational forms of bullying among German students: age trends, gender differences, and correlates. Aggressive Behaviour 2006 June; 32(3): 261-275.

13. Maliki AE, Asagwara CG, Ibu JE.Bullying problems among school children. Journal of Human Ecology 2009, 25(3): 209-213.

14. Hazler RJ, Hoover JH, Oliver R. What kids say about bullying. Executive Educator 1992; 14 (11): 20 - 22. 